\title{
Blind Belt using Ultrasonic Sensor
}

\author{
Arwinanto Sitohang, Ignatius Visnu, Indra Eka Prayoga, Erwin Sitompul, Hendra J. Tarigan \\ Department of Electrical Engineering, President University, Bekasi 17550, Indonesia \\ Emails: arwinajjha@gmail.com, visnuignatius0@gmail.com, ipmanprayoga443@gmail.com, sitompul@president.ac.id, \\ tarigan@president.ac.id \\ Corresponding author: arwinajjha@gmail.com
}

\begin{abstract}
Vision impairment has been common phenomena in this day and age. Many people suffer from this impairment with only a few technological supports to help them in daily life. This project created prototype to help people with vision impairment navigating through space. Built in the form of a belt, this project uses Ultrasonic sensor to detect the surrounding object. It uses three ultrasonic sensors attached to the front, left, and right area of the belt. Whenever an object is detected near any of these three areas, buzzer will be ringing. The buzzer is set in three different tones such that the wearer knows which side of the belt the object is.
\end{abstract}

Keywords: Vision, Impairment, Ultrasonic, Belt.

\section{Introduction}

Technology can be useful in helping our everyday lives, especially some of us who need extra helps in doing daily activities. Blindness is an example of difficulties some people face in their lives. It can be obtained since birth, or one can lose his sight at a point in their live. There are many reasons that can make this happen. The following eye diseases and conditions can cause blindness:

1. Glaucoma refers to different eye conditions that can damage your optic nerve, which carries visual information from your eyes to your brain.

2. Macular degeneration destroys the part of your eye that enables you to see details. It usually affects older adults.

3. Cataracts cause cloudy vision. They're more common in older people.

4. A lazy eye can make it difficult to see details. It may lead to vision loss.

5. Optic neuritis is inflammation that can cause temporary or permanent vision loss.

6. Retinitis pigmentosa refers to damage of the retina. It leads to blindness only in rare cases.

7. Tumors that affect the retina or optic nerve can also cause blindness.

Blindness is a potential complication if you have diabetes or have a stroke. Other common causes of blindness include:

1. Birth defects.

2. Eye injuries.

3. Complications from eye surgery.

4. Causes of blindness in infants.

The following conditions can impair vision or cause blindness in infants:

1. Infections, such as pink eye.

2. Blocked tear ducts.

3. Cataracts.
4. Strabismus (crossed eyes)

5. Amblyopia (lazy eye).

6. Ptosis (droopy eyelid).

7. Congenital glaucoma

8. Retinopathy of prematurity (ROP), which occurs in premature babies when the blood vessels that supply their retina aren't fully developed.

9. Visual inattention, or delayed development of your child's visual system.

Realizing there are various causes and possibilities that can turn one blind, we know we have to make some improvements to address this problem. This problem can be troublesome to the sufferers, as he can't see things. That includes the inability of knowing things near him, as it can make him hit those objects. For example, a blind man can't spot a wall or pole as he walks. He will be just hitting those objects. People included in those things. The blind man can hit them as he walks, not knowing there are people beside him. Not only him, but people can get the problems too, if the blind man just walk into them.

This device would help such case, in which objects in a certain radius can be detected with ultrasonic. And buzzer will sound to alert the user. In this way, the blind will be helped so he won't just walk to objects and hurt themselves. Using this special belt, he can know if there are objects nearby. This device will be helpful for such people.

\section{Basic Theory}

\section{A. Microcontroller}

Arduino Uno ATMega 328p R3 is used in this project as the microcontroller to process input from the sensor into the LCD. Arduino Uno Board is a microcontroller board that uses microcontroller chip, software and hardware. It is fairly easy to use, suitable for begginers. There are 14 digital input/output pins, 6 analog inputs, a $16 \mathrm{MHz}$ quartz crystal, a USB connection, a power jack, an ICSP header and a reset button. By simply connecting it with your computer or 
power bank with USB cable, you can start creating things as you have many things you need already to support the microcontroller. The battery/power bank should be AC to DC.

Table 1. Arduino Specifications

\begin{tabular}{|l|l|}
\hline Microcontroller & ATmega328P \\
\hline Operating Voltage & $5 \mathrm{~V}$ \\
\hline Input Voltage (Recommended) & $7-12 \mathrm{~V}$ \\
\hline Input Voltage Limit & $6-20 \mathrm{~V}$ \\
\hline Pin I/O Digital & $\begin{array}{l}14(6 \text { of which can be used as } \\
\text { PWM outputs) }\end{array}$ \\
\hline Analog Input Pin & 6 \\
\hline Clock Speed & $16 \mathrm{MHz}$ \\
\hline Weight & $25 \mathrm{~g}$ \\
\hline
\end{tabular}

Arduino ATMega328 have PORTB, PORTC, and PORTD. These are the PORTs. There are also 23 pins for input and output. The following is a picture of Arduino complete with the pins.

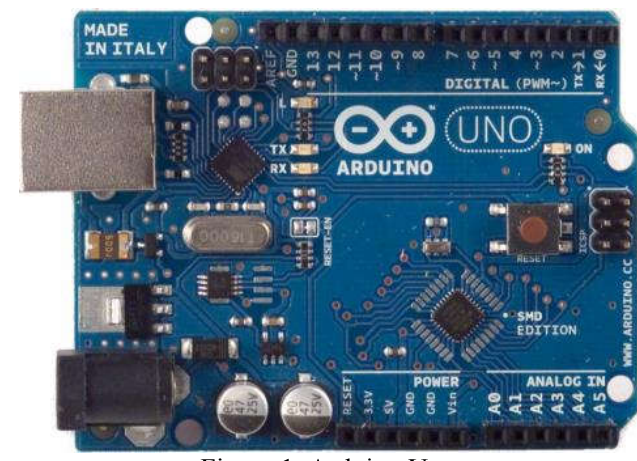

Figure 1. Arduino Uno.

\section{B. Breadboard}

Breadboard is a board used to make electronic circuits without soldering to connect wires/tools that we want to connect. The electronic components are safe from damages and usable for your next projects or circuits you want to create. This breadboard is made of plastic full of holes to plug wires or tools feet like LED or resistor feet.

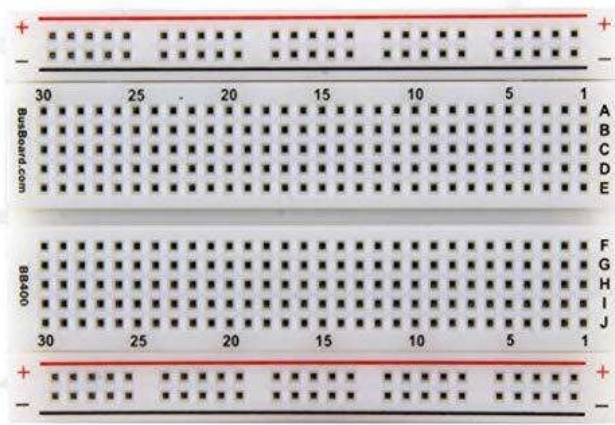

Figure 2. Breadboard.

\section{Wires}

Cables are used here to connect things in the electronic circuit, as we use breadboards and Arduino. We only use typical cables, which are male to male. We use scissors to cut them to be our desired sizes.

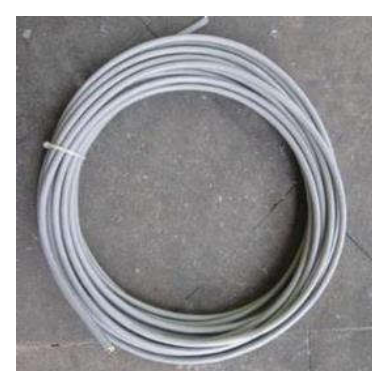

Figure 3. Wire

\section{Ultrasonic Sensor HC-SR04}

Ultrasonic sensor is a sensor that utilizes ultrasonic waves. This ultrasonic sensor consists of an ultrasonic transmitter circuit called a transmitter and an ultrasonic receiver circuit called a receiver. Ultrasonic waves are acoustic waves that have frequencies ranging from $20 \mathrm{kHz}$ to about $20 \mathrm{MHz}$. The working frequency used in ultrasonic waves varies depending on the medium traversed, ranging from low density in the gas phase, liquid to solid. If ultrasonic waves travel through a medium. The circuit of this ultrasonic sensor consists from the transmitter, receiver, and comparator. In addition, ultrasonic waves are generated by a thin piezoelectric crystal.

1. Piezoelectric

Piezoelectric equipment directly converts electrical energy into mechanical energy. The input voltage used causes the ceramic parts to stretch and emit ultrasonic waves. The type of transmission operation is piezoelectric element around $32 \mathrm{kHz}$ frequency.

2. Transmitter

Transmitter is a device that functions as an ultrasonic wave transmitter with a frequency of $40 \mathrm{kHz}$ generated from a 7 oscillator.

3. Receiver

The receiver consists of an ultrasonic transducer using piezoelectric material, which functions as a receiver of reflected waves originating from the transmitter which is worn on the surface of an object or direct wave LOS (Line of Sight) of the transmitter.

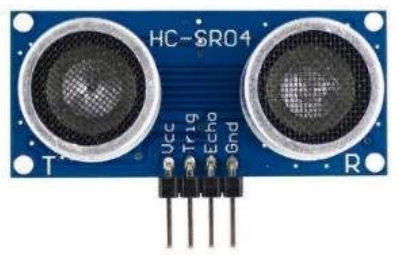

Figure 4. Ultrasonic Sensor.

\section{E. Buzzers}

A "piezo buzzer" is basically a tiny speaker that you can connect directly to an Arduino.

"Piezoelectricity" is an effect where certain crystals will change shape when you apply electricity to them. By applying an electric signal at the right frequency, the crystal can make sound.

If your buzzer has a sticker on top of it, pull the sticker off. Connect one pin (it doesn't matter which one) to the Arduino's ground (GND) and the other end to digital pin 8 . From the Arduino, you can make sounds with a buzzer by 
using tone. You have to tell it which pin the buzzer is on, what frequency (in Hertz, Hz) you want, and how long (in milliseconds) you want it to keep making the tone.

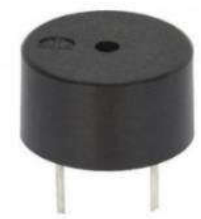

Figure 5. Buzzer.

\section{System Design}

\section{A. Hardware implementation}

The system design can make the system design of this tool more understandable. Ultrasonic sensor is as input. Then it is processed with Arduino using ATMega328 microcontroller. Buzzer is the output tool.

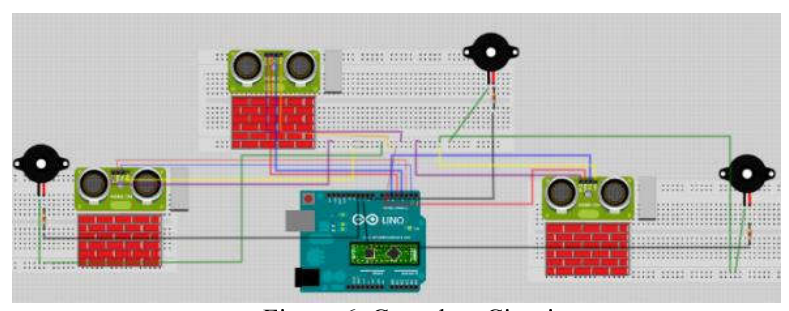

Figure 6. Complete Circuits.

The system workflow can be seen in Figure 7 .

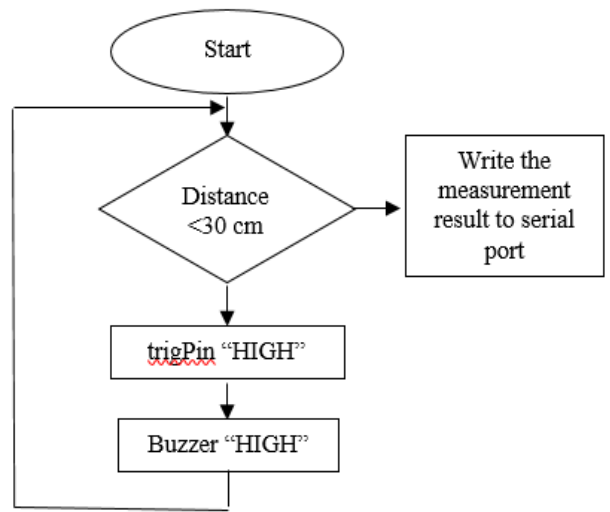

Figure 7. Circuit Chart.

B. Software Implementation

The program of the prototype can be seen in Table

2.

Table 2. Arduino Code

\#define trigPin 1

\#define echoPin 2

\#define trigPin2 3

\#define echoPin2 4

\#define trigPin 35

\#define echoPin3 6 \#define buzzer 9

\#define buzzer2 10

\#define buzzer3 11

void $\operatorname{setup}()$

\{

Serial.begin (9600);

pinMode(trigPin, OUTPUT);

pinMode(echoPin, INPUT);

pinMode(trigPin2, OUTPUT);

pinMode(echoPin2, INPUT);

pinMode(trigPin3, OUTPUT);

pinMode(echoPin3, INPUT);

pinMode(buzzer, OUTPUT);

pinMode(buzzer2, OUTPUT);

pinMode(buzzer3, OUTPUT);

\}

void loop() \{

int duration, distance;

digitalWrite (trigPin, HIGH);

delayMicroseconds (10);

digitalWrite (trigPin, LOW);

duration = pulseIn (echoPin, HIGH);

distance $=($ duration $/ 2) / 29.1$;

Serial.print(distance);

Serial.print("cm");

Serial.println();

if (distance < 30) $\{/ /$ Change the number for long or short distances.

digitalWrite (buzzer, HIGH);

\} else \{

digitalWrite (buzzer, LOW);

\}

int duration2, distance2;

digitalWrite (trigPin2, HIGH);

delayMicroseconds (10);

digitalWrite (trigPin2, LOW);

duration $=$ pulseIn $($ echoPin $2, \mathrm{HIGH})$;

distance $2=($ duration/2) $/ 29.1$;

Serial.print(distance2);

Serial.print("cm");

Serial.print $\ln ()$;

if (distance $2<30)\{/ /$ Change the number for long or short distances.

digitalWrite (buzzer2, HIGH);

\}

else \{

digitalWrite (buzzer2, LOW);

\} 


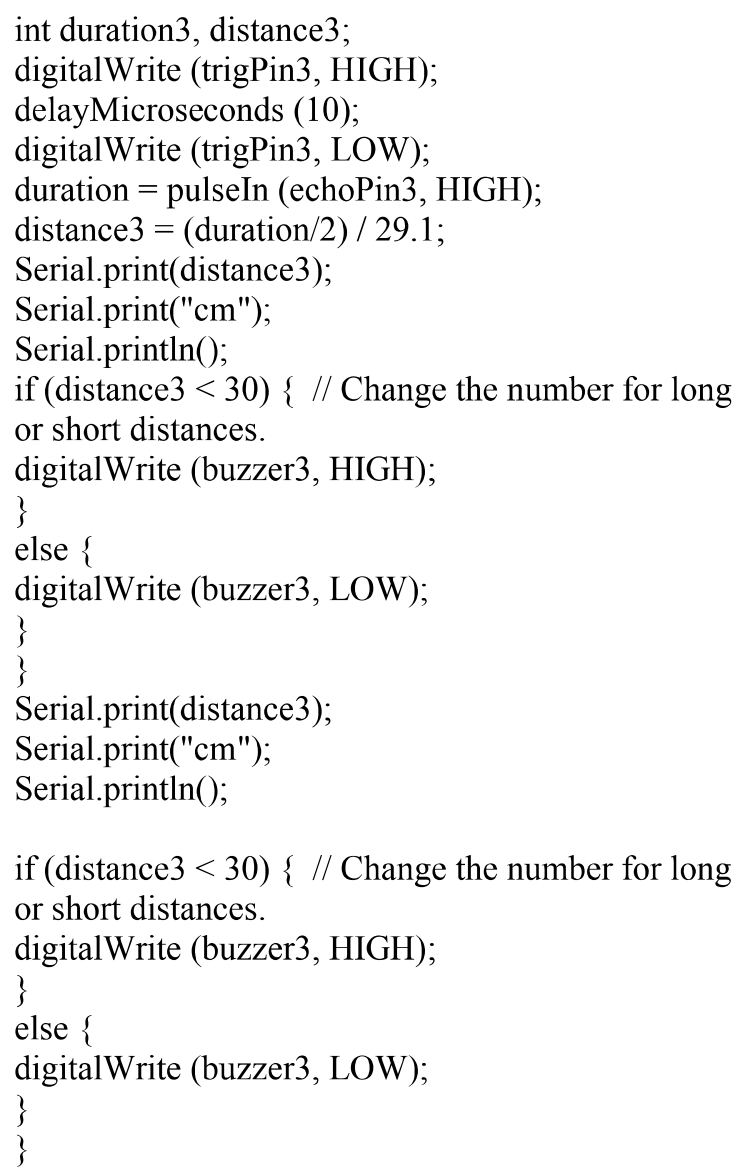

For the first box, we declare the Arduino pin used for this project, As you can see because we are using 3 Ultrasonic Sensor so there we must declare that we are using 6 pin for trigger pin and echo pin for 3 sensor, and also declare the pin we use for the buzzer

The second Box on the void setup we declare that the trigPin and echoPin from sensor as the input for Arduino, and the same also with the buzzer we declare first that the buzzer is output for Arduino

On the void loop, we input the int duration, and distance to control how fast will the sensor shoot the signal and receive and how far is the distance. In the program we set the time sensor will shoot the signal is 10 microseconds from the last receiving signal.

The next step is putting the distance it gets from every sensor in serial port, because we already write the serial begin, we can see the serial port showing the result measurement from the sensor and in this program, we set the unit to centimeter.

After that, the maximum distance is set for the trigPin to set high, in here we set the maximum distance is $30 \mathrm{~cm}$ so if there is something from less than $30 \mathrm{~cm}$ the trigPin will in HIGH condition and it will activate the buzzer.

\section{RESULTS}

The result of this project is simple. When there are objects in the range of lower than $30 \mathrm{~cm}$, buzzer which are assigned to the respective ultrasonic sensors will sound. There are 3 buzzers for 3 ultrasonic sensors, which will make them work for only one ultrasonic sensor each that are connected to them. The blind belt should be worn outside the clothes so the sensors can detect objects accurately, and the power bank as the power source can be placed in the user's pocket. The device has been tested and assessed by the lecture of Embedded System course. Each buzzer has different sound so the user can differentiate the alerts for each direction. We also have tested it by using it walking to non-moving objects such as walls and to moving objects such as people. The prototype does its job accurately, as it detects all of the objects in the range and send outputs.

As this is only a prototype, this has some drawbacks. First, the user's movement and mobility would be somewhat limited, as if he moves his arms to in front of the sensors, the buzzers will be sounded and it would be a fake alert for him. Second, this prototype wouldn't help much if the blind user wants to cross a road. With the distance of objects needs to be less than 30 , the user wouldn't have time to walk faster if there are speeding vehicles moving towards him.

\section{CONCLUSION}

In conclusion, although this prototype has some drawbacks, the core use and aim are on spot. We proved that electronic sensors, in this case ultrasonic sensor, can be used to help our lives and make it somewhat better, specifically improving the lives that need this kind of device. We hope that this idea can also make people feel that electrical engineering is not all about violent explosions, hard formulas, and getting electrocuted. There are things electronics can do to make things easier. And this device would be a way of hope to improve the lives of blind people.

\section{REFERENCES}

[1] S.J. Kang, et al." Development of an Intelligent GuideStick for the Blind", Proceeding of the IEEE international Conference on Robotics \& Automation, 2001.

[2] Y. Kawai and F. Tomita, "A support system for visually impaired persons to understand three-dimensional visual information using acoustic interface", IEEE Conference on Pattern Recognition, Vol. 3, pp. 974-977, 2002.

[3] A. Rodriguez, et al., "Obstacle avoidance system for assisting visually impaired people", in proceeding IEEE Intelligent Vehicles Symposium Workshop, 2012.

[4] S. Dambhare, et al., "Smart stick for Blind: Obstacle Detection, Artificial vision and Real-time assistance via GPS", 2nd National Conference on Information and Communication Technology (NCICT), 2011.

[5] M. Hazzaz, et al., "Smart Walking Stick- an electronic approach to assist visually disable persons", International Journal of Scientific \& Engineering Research, vol. 4, No. 10, 2013. 


\title{
IOT-Based Smart Lamp Using Arduino
}

\author{
Diviandi Muhammad, Ghalib Eko Prasetyo, Muhammad Ferrizal Ramadhan, Antonius Suhartomo \\ Department of Electrical Engineering, President University, Bekasi 17550, Indonesia \\ Email: diviandimuhammad@gmail.com,ghalib12223@gmail.com, ferriza199@gmail.com, asuharto@president.ac.id \\ Corresponding author: diviandimuhammad@gmail.com
}

\begin{abstract}
This project is the application of IoT for home appliances, in particular lighting. The prototype is making use NodeMcu as the main controller and free to use IoT platform BLYNK. The combination of these two provides capabilities to control the lamp(s) remotely using smartphone connected to the Internet. The prototype uses Google Assistant to turn on and turn off the lamp remotely using voice command.
\end{abstract}

Keywords: IoT, NodeMCU, Google Assistant, Lamp, remote, BLYNK.

\section{Introduction}

IoT is the use of technology in the future that uses the internet network to develop existing technology to make it easier to use and has many functions. In the future every home will use IoT technology to make it more comfortable to live in. So, with the internet we make "Smart Lamp" based on IoT for operating lights at home.

Smart Lamp is an amalgamation of relay and NodeMcu for the use of lights at home. In its use the lamp will be able to operate using mobile phones and the internet via the google assistance command. Through google assistance we can command the lamp by saying "Hello Google, turn on the lamp" then google will give the answer "OK boss" coupled with the lights on Then to turn off the lights we say "Hello Google, Turn off the lamp" then google will answer "Good night, Have a nice dream" coupled with the lights go oult. Our tools can help people's desires to be able to monitor the use of electricity the use of lamps becomes easier.

\section{Basic Theory}

\section{A. NodeMCU}

In this project we use NodeMCU. NodeMCU is an open-source IoT platform that uses the ESP8266 chip and uses the Lua scripting programming language. Basically, NodeMCU is a microcontroller that is added to the LX106 Wi-Fi module which is combined into a compact form, which in its use can be control with mobile phones through the internet network.

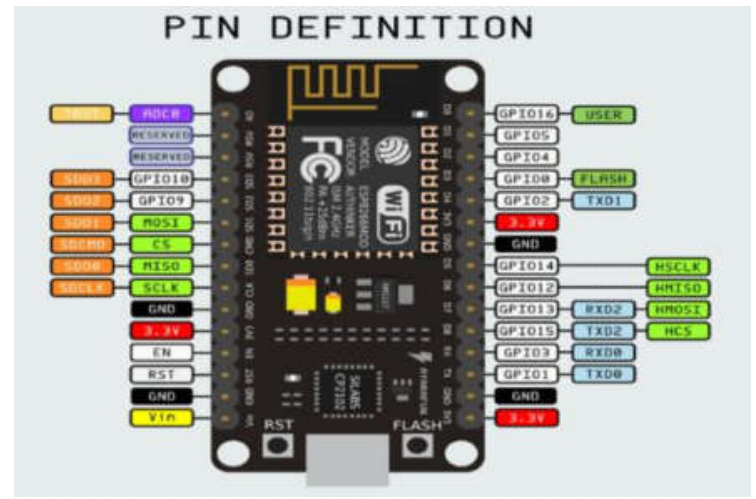

Figure 1. NodeMCU Pin Definition.

As can be seen in Figure 1, some main features of NodeMCU

1. 10 Port GPIO form D0 - D10

2. PWM Function

3. Interface $\mathrm{I} 2 \mathrm{C} \& \mathrm{SPI}$

4. $\mathrm{ADC}$

The use of NodeMCU and Arduino is very similar, but the NodeMCU already has several features already integrated on the board such as the $\mathrm{Wi}-\mathrm{Fi}$ feature where when using Arduino we have to add a Wi-Fi module where it is not easy and troublesome because we have to install the cable and port Wi-Fi module on Arduino but the NodeMCU feature is already installed and we just use it.

\section{B. Relay}

Relays can be used to connect and disconnect the currents according to what we want. Relays can also be used as timers to perform tasks in turn. This can be done because the relay has NO (Normally Open) and NC (Normally Close) ports that can be controlled by a microcontroller and then developed to be many things. Basic construction of relay can be seen in Figure 2. 

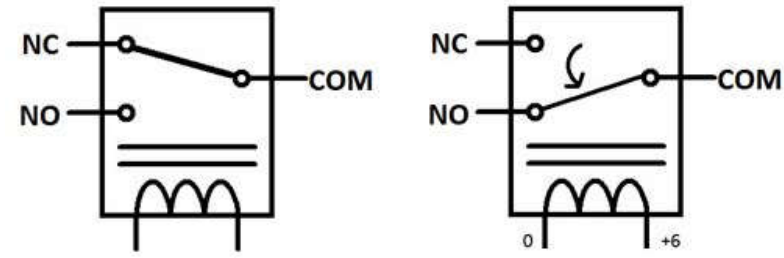

Figure 2. Construction of relays

The operations of relay is as follows; when the coil is given a voltage, the coil position will be $\mathrm{NC}$ which makes the current pass through the relay but when the coil does not get the voltage the coil position will be NO so that no current can pass through the relay and you can choose what position you want to use.

Pin connections for relay for $\mathrm{AC}$ and $\mathrm{DC}$ circuit is shown in Table 1.

Table 1. Pins for Relay

\begin{tabular}{|l|l|}
\hline AC & DC \\
\hline $\begin{array}{l}\text { COMM (common pin for source of } \\
\text { voltage) }\end{array}$ & GND \\
\hline PIN NO (Normally Open) & VCC(3.3 volt) \\
\hline PIN NC (Normally Close) & IN (data from microcontroller) \\
\hline
\end{tabular}

\section{LED Lamp}

In this project we use LED lights with voltage $220 \mathrm{~V}$ and 12 watts. The use of LED lights is so that the electricity used is lower and more efficient then in longterm use is more durable. Led lights are also not hot so it is safer when errors occur in. An example of LED lamp is shown in Figure 3.

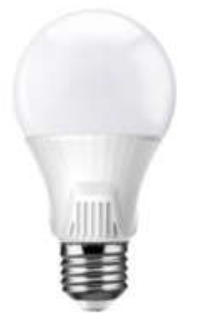

Figure 3 LED Lamp.

\section{System Design}

\section{A. Hardware Implementation}

The Prototype design for this project can be seen in Figure 4.

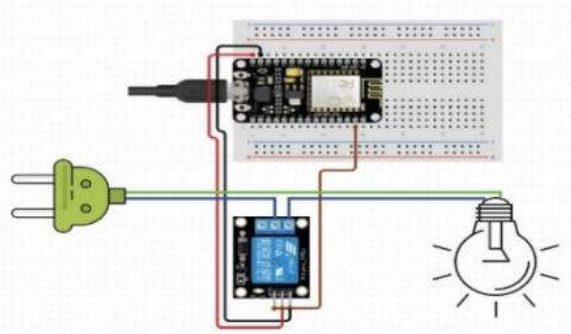

Figure 4. System Design.
The system workflow can be seen in Figure 5.

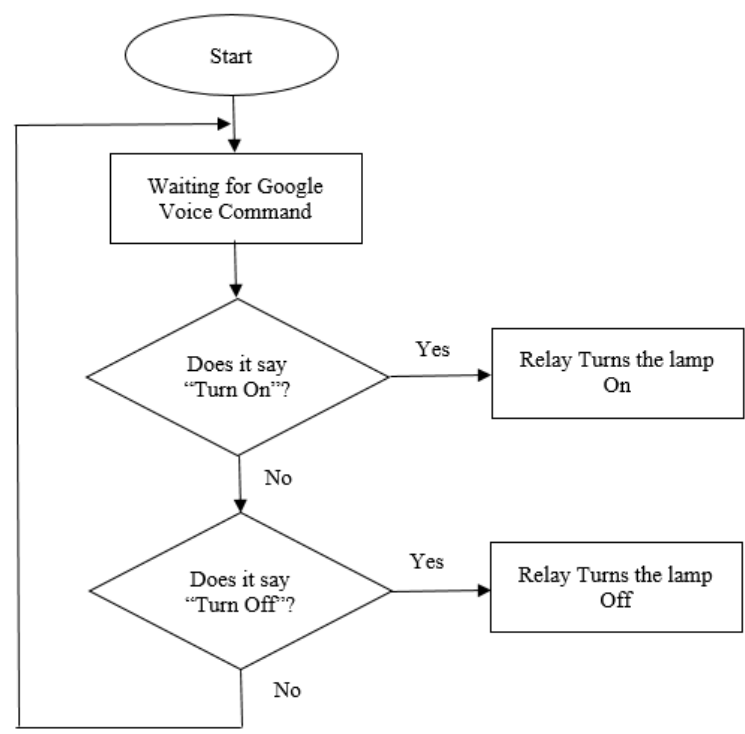

Figure 5. System Flow Chart.

\section{B. Software Implementation}

Besides the hardware that we use, there are some software application like IFTTT (If This Then That) and BLYNK.

Actually, there are many applications that we use to help us to work, but for the IFTTT and BLYNK are the core.

\section{IFTTT}

IFTTT is a software or we can say web-based services that help us to create chains of simple conditional statements that called applets. The benefits that really help us because it's free and easy to access, so for us that want to try will not make any difficulties. It provides so many connections to some webs and applications services, that will not make limitation to our creativity. In this module of projects, we make connection to webhooks.

This platform also provides Goggle Assistant option to trigger a pre-defined event such as turning on and off the lamp. An example of such configuration is shown in Figure 6.

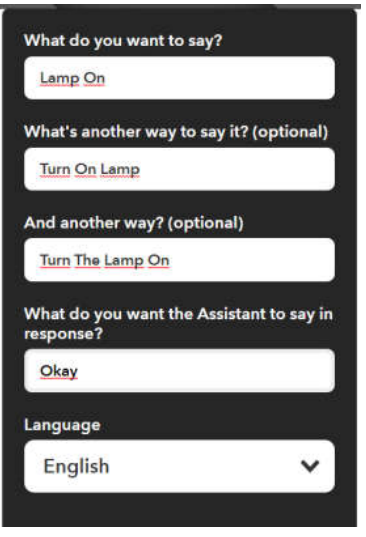

(a)

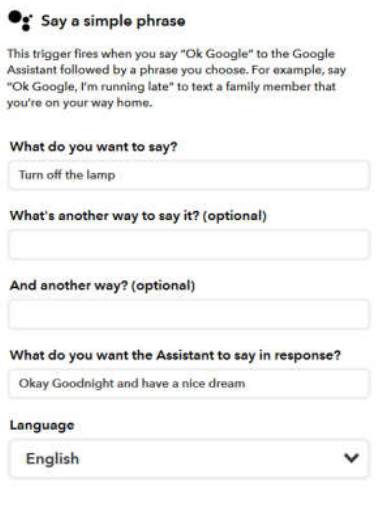

(b)
Figure 6. IFTTT Setup for (a) turning on the lamp and (b) turning off the lamp. 


\section{BLYNK}

BLYNK (see Figure 7) is another application that we use, that the use is in our mobile phone that so easily we find. It can be found in playstore for android user and iOS for iPhone. BLYNK is one of the applications of IoT, that connects module to internet so easily. Another benefits that given is we can make diagnostic by private clouds, giving data analytics, and machine learning. It also can connect us to many applications and webs.

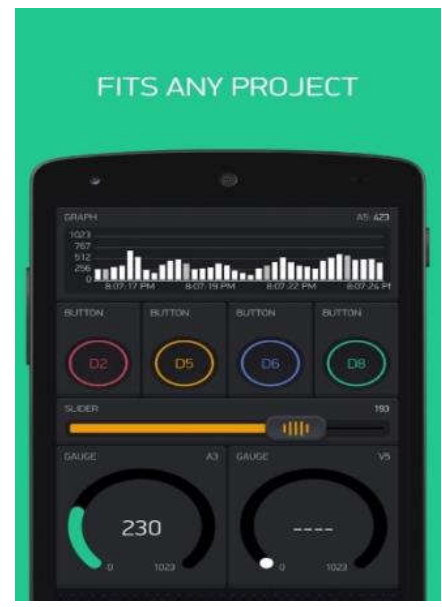

Figure 7. Front view of BLYNK application.

\section{Microcontroller Code}

Besides the web-side of software, the microcontroller also needs to be set up to connect properly to BLYNK. The code for NodeMCU is using the same language as Arduino. An example of script connecting NodeMCU to BLYNK is shown in Table 2.

\section{Table 2. NodeMCU Code}

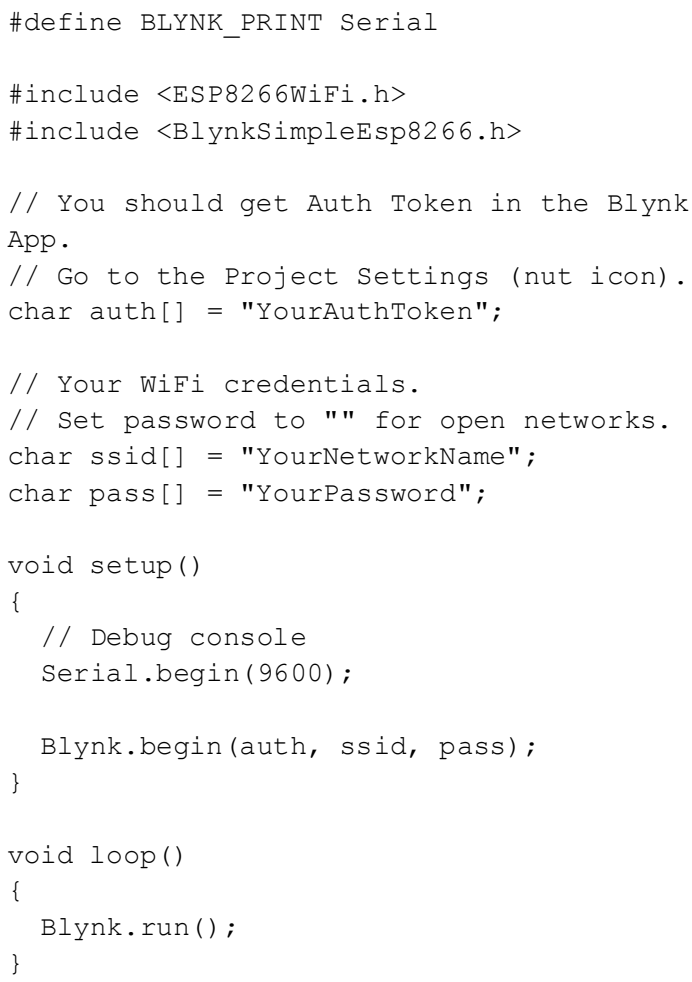

\section{RESULTS}

In order to see how the device works, an android phone signed in using the same google account as the IFTTT We have to use android phone that signed in with the same google account as in the IFTTT website.

Saying "Turn on the lamp" will trigger the Webhooks to set the pin value to " 1 " that will trigger the relay and turn the lamp on as can be seen in Figure 8.

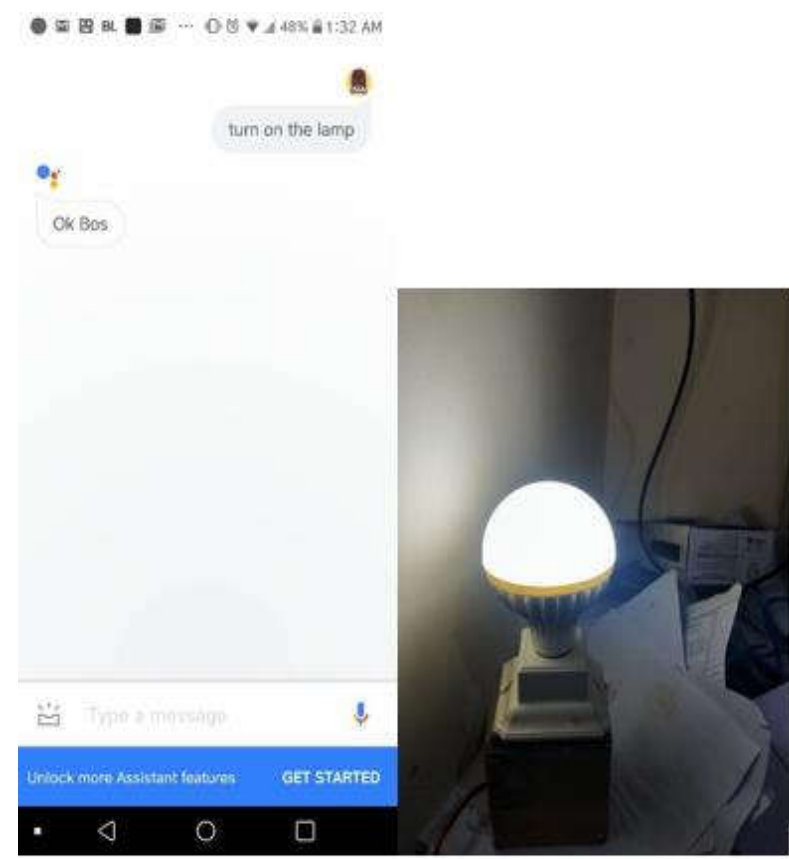

Figure 8. Device Testing (turning on the lamp).

Similarly, to turn off the lamp, one can say, "Turn off the lamp" and the Webhooks will trigger the relay to turn off the lamp as shown in Figure 9.

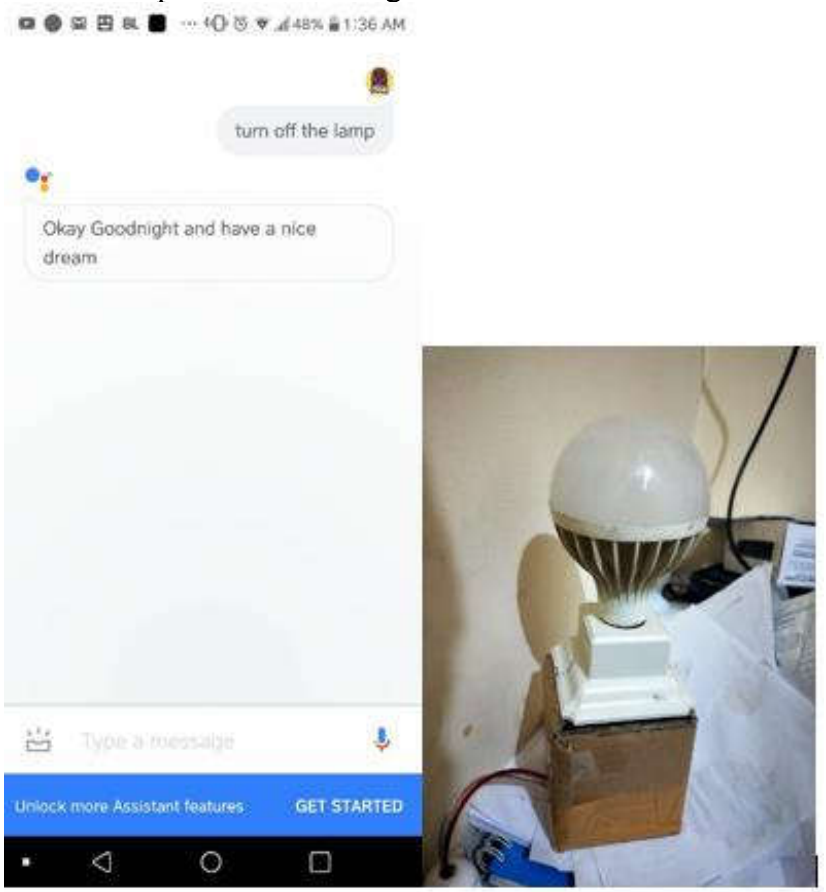

Figure 9. Device Testing (turning off the lamp). 


\section{CONCLUSION}

The innovation of IoT is very huge right now, it is spreading to many sectors such as sports, industry, home, etc. These are affected by the human needs, but time by time technology and environment force us to make any innovation that effective and useful. So basically, this project is very important for our life, within this benefit actually so many things we can do easily.

Example, smart lamp is great innovation that actually can help many people, to simplify our work. Besides so many benefits given, the manufacture of the smart lamp is very easy that maybe everyone can install. Within any further, we can customize as we need that maybe in the next progress the use of it will help more people.

\section{REFERENCES}

[1] Nodemcu,

2017 ,

[online]

Available: http://www.nodemcu.com/. (Accessed: 10th December 2017).

[2] A. Adriansyah, A.W. Dani, "Design of Small Smart Home Control Systems Based on Wireless Sensor Networks and Power Line Communications", IEEE, 2014.

[3] K. Baraka, et.al., "Low cost Arduino/Android-based Energy-Efficient Home Automation System with Smart Task Scheduling", Fifth International Conference on Computational Intelligence, 2013.

[4] C.F. et al., "The Internet of Things", First International Conference, 2008.

[5] D. Zeng, S. Guo, Z. Cheng, "The Web of Things: A Survey", Journal of Communications, 2011. 